\title{
Aortic Leaflet Perforation During Radiofrequency Ablation
}

\author{
MARK J. SEIFERT, ${ }^{*}$ FRED MORADY, ${ }^{* *}$ HUGH G. CALKINS, ${ }^{* *}$ and \\ JONATHAN J. LANGBERG** \\ From the ${ }^{*}$ Division of Internal Medicine and the ${ }^{*}$ Division of Cardiology, University of \\ Michigan Medical Center, Ann Arbor, Michigan
}

\begin{abstract}
SEIFERT, M.J., ex AL.: Aortic Leaflet Perforation During Radiofrequency Ablation. A 15-year-old girl underwent successful radiofrequency ablation of an accessory pathway. Following ablation, a new III/VI diastolic murmur was noted. Echocardiography revealed a perforated aortic leaflet, with a small amount of adherent valvular tissue and trivial aortic insufficiency by color Doppler. The patient remains asymptomatic. We are not aware of any similar complication from electrophysiological study, catheter ablation, coronary angiography, or percutaneous transluminal coronary angioplasty. We speculate that the current state of catheter technology contributed significantly to this complication. This case illustrates the need for using care in crossing the valve, continued advances in catheter technology to reduce the incidence of complications, and careful physical examination prior to and following attempts at ablation. (PACE, Vol. 14, November, Part I 1991)
\end{abstract}

Wolff-Parkinson-White syndrome, catheter, complication, ablation, radiofrequency, valve

\section{Introduction}

Recent advances in electrophysiology have included radiofrequency catheter ablation of accessory pathways. Preliminary reports suggest that catheter ablation in the Wolff-Parkinson-White (WPW) syndrome is effective and complications are rare. ${ }^{1-3}$ We describe an unusual case of perforation of an aortic valve leaflet during radiofrequency catheter ablation of a left-sided accessory pathway in a 15-year-old girl.

\section{Case Report}

A 15-year-old girl with WPW syndrome was referred for catheter ablation of a left posterolateral accessory pathway. She had an 18-month history of exertional palpitations including one episode of

Address for reprints: Jonathan J. Langberg, M.D., Division of Cardiology, University of Michigan Medical Center, 1500 East Medical Center Drive, Ann Arbor, MI 48109. Fax: (313) 9367641.

Received February 27, 1991; revision June 20, 1991; accepted August 16, 1991. near syncope during competitive swimming. Baseline electrophysiological testing demonstrated a single left posterolateral accessory pathway. Orthodromic atrioventricular reentrant tachycardia was reproducibly induced. A hemostatic sheath was inserted into the right femoral artery, and a 7 French steerable quadripolar electrode with a large (length $4 \mathrm{~mm}$; surface area $27 \mathrm{~mm}^{2}$ ) distal electrode (Mansfield Scientific, Watertown, MA, USA) was advanced under fluoroscopic guidance without a curve until the tip reached the noncoronary cusp of the aortic valve. The catheter was then advanced without introducing a curve in the tip deflector until it prolapsed across the aortic valve, passing retrogradely into the left ventricle. The ablation catheter was positioned between the posterior leaflet of the mitral valve and the endothelium, advanced to the level of the annulus, and manipulated to the site of earliest ventricular activation. An electrosurgical unit (Radionics RFG 3B [Radionics Inc., Burlington, MA, USA]) was used to apply radiofrequency energy between the distal electrode of the catheter in the left ventricle and a large skin electrode. Voltage and current were continuously monitored during each application. 

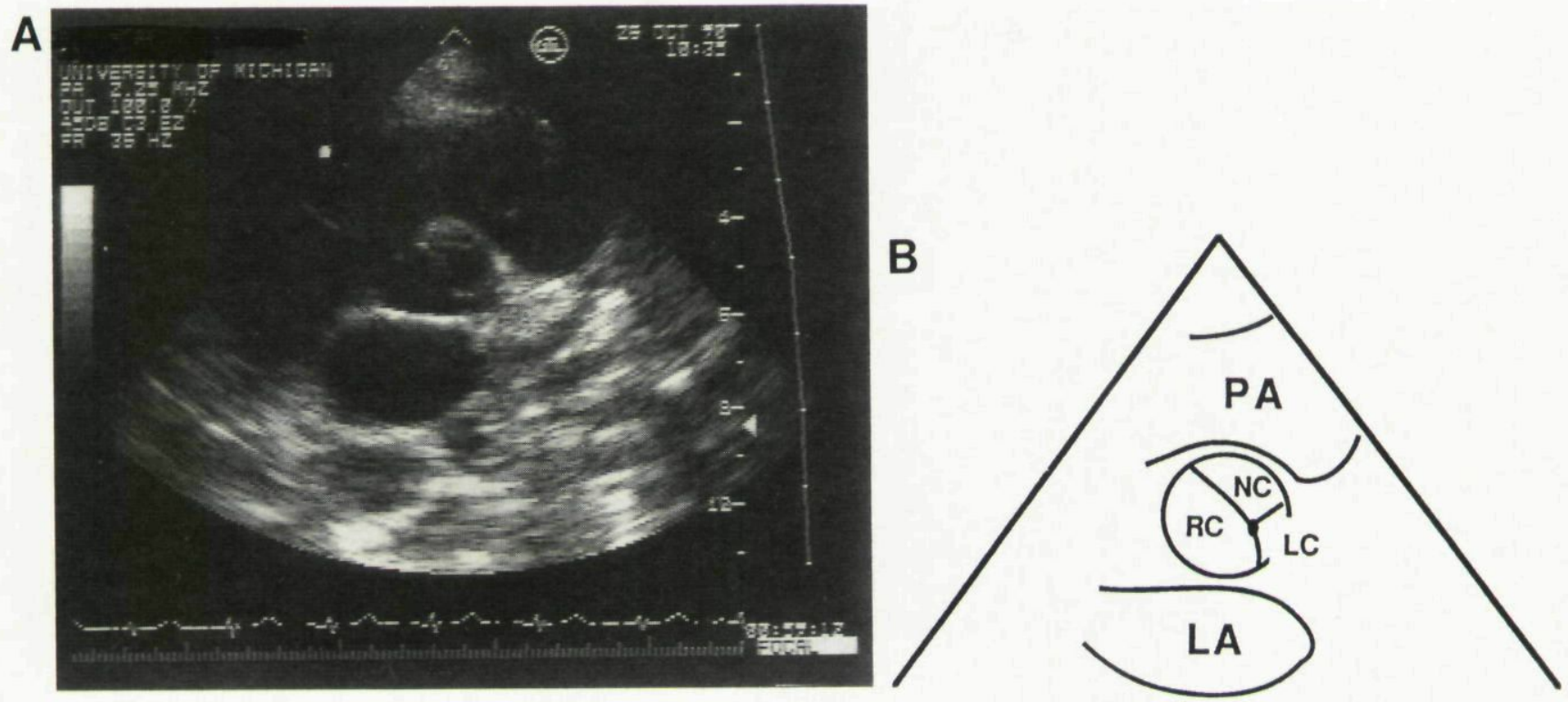

Figure 1. (A) Two-dimensional echocardiogram, parasternal short-axis view, in early systole showing the asymmetry of the aortic valve. (B) Diagram of A. LA = left atrium; LC = left coronary cusp; $\mathrm{NC}=$ noncoronary cusp; $\mathrm{PA}=$ pulmonary artery; $\mathrm{RC}=$ right coronary cusp.

The left posterolateral accessory pathway was successfully ablated with twenty applications of radiofrequency energy. During manipulation, the ablation catheter was inadvertently expelled into the aortic root seven times and, because of coagulum formation and impedance rise, had to be removed and the distal electrode cleaned three times. Thus, the catheter was prolapsed across the aortic valve a total of ten times during the course of the procedure. Following the procedure no antegrade or retrograde accessory pathway conduction could be demonstrated, and the ECG revealed no preexcitation. Physical examination revealed a new III/VI pandiastolic decrescendo murmur at the left lower sternal border. A Doppler echocardiogram revealed an asymmetric aortic valve with a normal size noncoronary cusp, a large right coronary cusp, and a diminutive left coronary cusp (Fig. 1). The left coronary cusp demonstrated a small central perforation with a flap of valvular tissue seen to prolapse during diastole (Fig. 2). There was trivial aortic insufficiency by color Doppler, which was localized to the site of perforation in the left coronary cusp (Fig. 3). The patient remained hemodynamically stable and symptom free. After 2 days of observation she was discharged with instructions to obtain antibiotic prophylaxis for dental and surgical procedures.

The patient was seen in follow-up 4 weeks after ablation. She reported some mild palpitations in the interval since her discharge, which an event recorder revealed to be rare premature atrial contractions. The physical examination revealed a barely perceptible I/VI aortic insufficiency murmur. Color Doppler and two-dimensional echocardiography at follow-up revealed persistent aortic insufficiency without significant change from the baseline study. The ECG revealed no evidence of preexcitation.

\section{Discussion}

We have described a patient with a left posterolateral accessory pathway and WPW syndrome who underwent successful radiofrequency catheter ablation of an accessory pathway. This procedure was complicated by perforation of an aortic valve cusp resulting in an aortic insufficiency murmur, which has become increasingly difficult to appreciate on physical examination, and trivial aortic insufficiency by Doppler echocardiography, which has remained stable. The pa- 

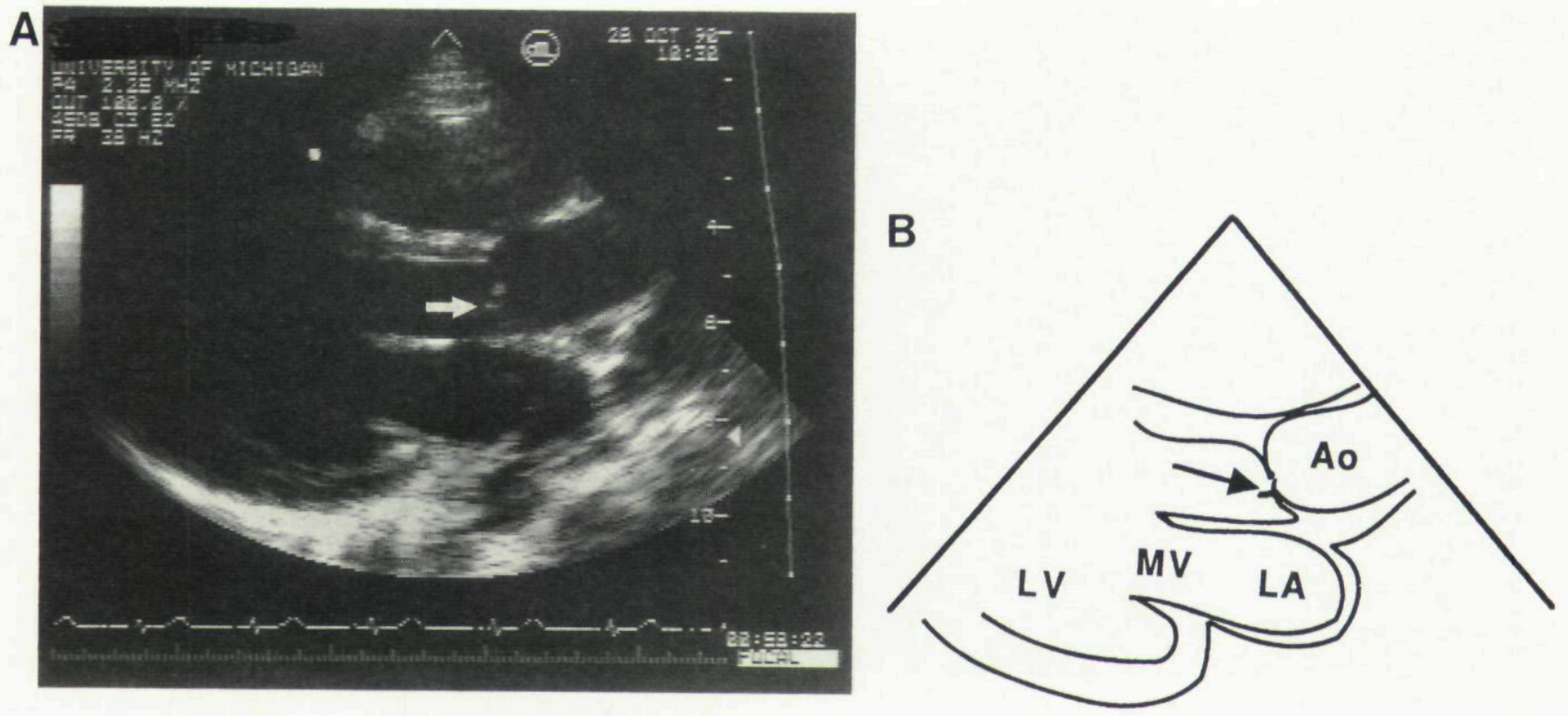

Figure 2. (A) Two-dimensional echocardiogram, parasternal left ventricular long-axis view, in mid-diastole demonstrating a small shred of aortic valve tissue, prolapsing below the plane of the valve into the left ventricle. (B) Diagram of A. Arrow indicates valvular tissue prolapsing out of the plane of the aortic valve into the left ventricle. Ao = aorta; $L A=$ left atrium; $L V=$ left ventricle; $M V=$ mitral valve.
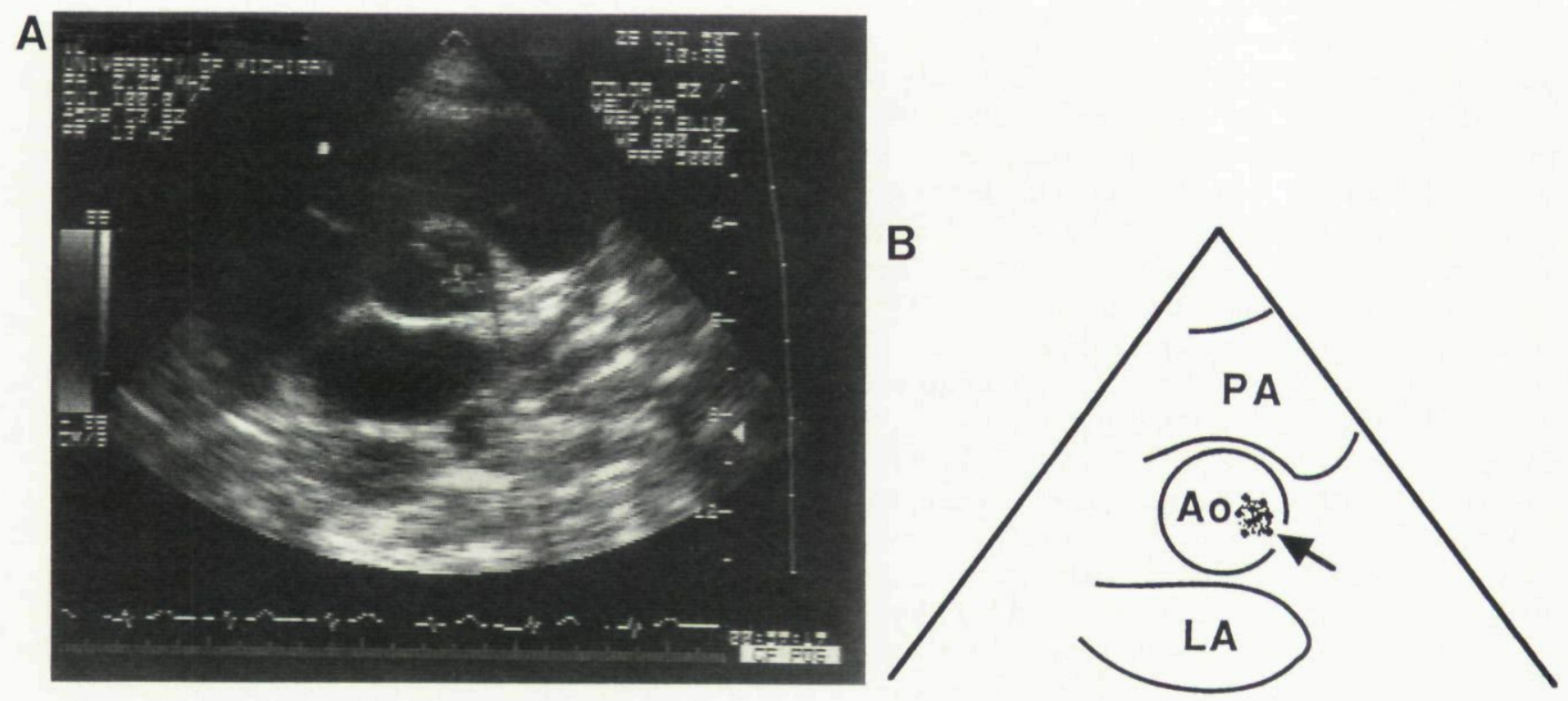

Figure 3. (A) Two-dimensional Doppler echocardiogram, parasternal short-axis view, in middiastole demonstrating trivial aortic insufficiency through a hole in the left coronary cusp. (B) Diagram of A. Arrow points to regurgitant jet seen on Doppler. Ao = aorta; LA = left atrium; $P A=$ pulmonary artery. 
tient continues to be asymptomatic. To our knowledge, perforation of a valve leaflet has not been previously reported as a complication of catheter ablation, electrophysiological study, coronary arteriography, or percutaneous transluminal coronary angioplasty.

Steerable electrode catheters presently available for radiofrequency ablation are relatively stiff. We speculate that the current state of catheter technology contributed significantly to perforation of the aortic leaflet. The significance of the patient's asymmetric aortic valve and the extent to which it may have predisposed her to valve leaflet

\section{References}

1. Kuck KH, Kunze KP, Schluter MG, et al, Ablation of a left-sided free-wall accessory pathway by percutaneous catheter application of radiofrequency current in a patient with the Wolff-Parkinson-White syndrome. PACE 1989; 12:1681-1690.

2. Jackman WM, Wang X, Friday KJ, et al. Catheter ablation of atrioventricular pathways (Wolff-Parkin- perforation is unknown. It is possible that by monitoring temperature at the distal electrode the risk of coagulum formation at the catheter tip could be minimized, reducing the number of valve crossings required for ablation. This case serves to illustrate the importance of continued advances in catheter technology that would permit effective ablation while reducing the incidence of complications. This case also demonstrates the need for using care in crossing the aortic valve during ablation of accessory pathways via the left ventricular approach, and for physical examination prior to and following attempts at catheter ablation.

son-White syndrome) by radiofrequency current. N Engl J Med 1991; 324:1605-1611.

3. Calkins HG, Sousa J, El-Atassi R, et al. Diagnosis and cure of the Wolff-Parkinson-White syndrome or paroxysmal supraventricular tachycardias during a single electrophysiologic test. N Engl J Med 1991; 324:1612-1618. 
Copyright of Pacing \& Clinical Electrophysiology is the property of Blackwell Publishing Limited and its content may not be copied or emailed to multiple sites or posted to a listserv without the copyright holder's express written permission. However, users may print, download, or email articles for individual use. 